\title{
Comparative assessment of different marketed brands of atorvastatin tablets in Asir region, Saudi Arabia
}

\begin{abstract}
The main purpose of the study is to evaluate the quality of different marketed products of Atorvastatin calcium tablets available in the Middle East in Asir region, Kingdom of saudi Arabia, with a view to determine their interchangeability in clinical practice. Survey of the assessed Atorvastatin brands was carried out in south western cities of Saudi Arabia based on their prices. Drug products' quality assessment included visual examination for their organoleptic properties; official and non-official quality control tests, dissolution profile, mechanism and kinetics release. The results show that Code A (Liptor TM, European sourced) samples were more expensive than the other samples, it is almost double the price of sample B (Lorvast) and C (Lipomax). All the results of marketed brands pass the tests. Comparison of in vitro drug dissolution profile of all samples shows approximately $90 \%$ drug release within $1 \mathrm{hr}$, whereas sample A and C show $100 \%$. The release mechanism and kinetics from the samples $\mathrm{A}$ and D (Astatin) are Non-fickian diffusion and 1st order release, sample B and C shows Fickian diffusion and 1st order and peppas release respectively. From these results it was concluded that all samples of Atorvastatin calcium tablets may be interchangeable with other in Asir region.
\end{abstract}

Keywords: atorvastatin, dissolution studies, release mechanisms, kinetic release
Volume 2 Issue I - 2018

\author{
Mohamed Rahamathulla \\ Department of Pharmaceutics, King Khalid University, Saudi \\ Arabia
}

Correspondence: Mohamed Rahamath Ulla, Department of Pharmaceutics, King Khalid University, Saudi Arabia, Tel 009-665958-04I-87,Email rahapharm@gmail.com

Received: January 28, 2018 | Published: February 08, 2018

\section{Introduction}

Atorvastatin (AVS) is lipid-lowering agent, which is selective, competitive inhibitor of 3-hydroxy-3-methylglutaryl-coenzyme. A reductase which catalyzes the conversion of HMG-CoA to mevalonate, which is a rate limiting step in cholesterol biosynthesis. AVS decreases the levels of low-density lipoprotein (bad cholesterol) and triglycerides in the blood, while enhancing the levels of highdensity lipoprotein (good cholesterol). ${ }^{1-2}$ The empirical formula of AVS calcium is $(\mathrm{C} 33 \mathrm{H} 34 \mathrm{FN} 2 \mathrm{O} 5) 2 \mathrm{Ca} 2+3 \mathrm{H}_{2} \mathrm{O}$ with a molecular weight of 1209.42, as shown in Figure 1. AVS is widely used to treat high cholesterol, to lower the risk of heart attack, myocardial infarction, angina, stroke, and other heart complications in people with type II diabetes and coronary heart disease. The dosage range of AVS is $10-80 \mathrm{mg}$ once a daily as a single dose with or without food at any time of the day. ${ }^{3-4}$ The starting recommended dose of AVS is 10-20mg once daily, rapidly absorbed after oral administration. The half-life is approximately $12 \mathrm{~h}$, extensively metabolized to ortho- and para-hydroxylated derivatives and various beta-oxidation products (cytochrome P450 3A4) in the liver (hepatic metabolism) and a small amount of the drug metabolates from urine, elimination is mainly through bile. ${ }^{5-7}$ Oral dosage forms are safest and commonest route of drug administration. The efficacy of the dosage systems can be assured when its quality is reliable. ${ }^{8}$ The efficacy of pharmaceutical dosage systems usually depends on their formulation and manufacturing techniques, therefore the quality of dosage system may vary. ${ }^{9-11}$ In this research to assess the quality/bioequivalence study of four different AVS marketed tablets $(10 \mathrm{mg})$ currently available in Asir region, kingdom of Saudi Arabia. They were chosen for the study to survey AVS tablets in terms of product quality and price difference in the various brands. This research was carried out for general organoleptic test, structural defects, and comparative evaluation of official and non-official quality control test such as thickness, diameter, friability, hardness, drug content uniformity, weight variation, in vitro dissolution studies, kinetic release of drug, and statistical analysis of AVS marketed/commercially available tablets, which is very useful for pharmacists and health care professionals in order to determine the interchangeability.

\section{Materials and methods}

\section{Materials}

Four different marketed brands/samples of Atorvastatin calcium tablets $(10 \mathrm{mg})$ were purchased from community pharmacy (drug store) in Abha city, Asir region. The samples were properly checked for their drug dose, manufacturing license number, batch numbers, manufacturing and expiry dates. They were coded as A-D the details of all samples were shown in Table 1. The other solvents and chemical used in the study was analytical grade.

\section{Methods}

These are the following official and non-official quality control tests $^{12}$ are carried out during the study of different marketed brands of AVS.

\section{Uniformity of weight}

According to USP, Twenty (20) tablets from each marketed brand tablets were randomly selected, individually weighed, and the average weight of the tablet was determined. 


$$
\% \text { Deviation }=\frac{\text { Average weight of tablet }- \text { Individual tablet weight }}{\text { Average weight of tablet }} \times 100
$$

\section{Hardness and friability}

A total of 10 tablets, randomly selected from each marketed brand were taken for the study. It is expressed in terms of Newton. The hardness of tablets was calculated by Erweka hardness tester. In friability 10 tablets were randomly selected, weighed (W) and placed in a Roche friabilator (Pharma test PTFE) and rotated at $25 \mathrm{rpm}$ for 4 $\min$ (100 revolutions). The tablets were taken out from the friabilator, de-dusted, and weighed again $\left(\mathrm{W}_{\mathrm{t}}\right)$. The percentage friability $(\% \mathrm{~F})$ of the tablets was calculated using the formula:

$$
\% F=\left[1-\left(W_{t} / W\right)\right] \times 100 \%
$$

\section{Thickness and diameter}

Erweka tester was used to determine the thickness and diameter of the tablets. An average of ten tablets from each formulation (batch) was taken. It is expressed in terms of millimeter.

\section{Drug content uniformity test}

In each marketed brand, 10 tablets were taken and powdered. The quantity equivalent to a single dose of the drugs was dissolved in $0.1 \mathrm{NHCl}$ solution, $\mathrm{pH} 1.2$ for $2 \mathrm{~h}$ with occasional shaking and diluted to $100 \mathrm{~mL}$ with $\mathrm{pH} 1.2 \mathrm{HCl}$. After filtration, $1 \mathrm{ml}$ of the filtrate was diluted to $10 \mathrm{~mL}$ with the $\mathrm{pH} 1.2 \mathrm{HCl}$. The absorbance was measured at the required $\lambda_{\text {max }} 246 \mathrm{~nm}$ using a UV visible spectrophotometer (V570, Jasco Corp).

\section{Disintegration test}

The apparatus consists of a basket made of transparent plastic or polyvinyl material, which has six tubes set with equal diameter and a wire mesh of stainless steel with uniform size. Small metal discs were used to enable immersion of the dosage form completely. The entire basket-rack assembly is connected to a motor, which is immersed in a vessel containing the dissolution medium $(0.1 \mathrm{NHcl})$ in which the disintegration test is to be carried out. The vessel is provided with a thermostat to regulate the temperature of the dissolution medium at $37 \pm 0.5^{\circ} \mathrm{C}$. One tablet was placed in each of the tube in the basket, the time required for complete disintegration of the tablet in each tube was determined. ${ }^{13-14}$

\section{In vitro drug release study}

The drug release rate from samples was carried out using USP dissolution testing apparatus-II (paddle type), using $900 \mathrm{ml}$ of $\mathrm{pH}$ $1.2 \mathrm{HCL}$ as dissolution medium, at $37 \pm 0.5^{\circ} \mathrm{C}$ and $100 \mathrm{rpm}$. Aliquots $(5 \mathrm{ml})$ were withdrawn at regular time intervals for $1 \mathrm{~h}$; sample was replaced by its equal volume of fresh dissolution medium to keep the sink condition. The samples were analyzed spectrophotometrically at 246nm. ${ }^{15-16}$ The release kinetics was fitted into various models using PCP dissolution v 2.08 software.

\section{Mechanism of drug release}

The various mathematical models can be useful for explaining the kinetics release of drug process from the dosage forms, the most favorable of these models is the one which best conforms to the experimental results. The ideal models express the release of drug from pharmaceutical dosage form resulting from a simple phenomenon, or when this phenomenon, by being the rate-limiting step (RLS), conditions all the methods occurring in the system. The release kinetics from the formulations were determined by finding the best fit of the release data to first order, zero order, matrix (Higuchi), Hixson-Crowell, and Korsmeyer- Peppas plots. Higuchi model evaluated various theoretical models to study release of low and high water soluble drugs included in the solid or semi-solid matrices. According to higuchi drug release, it is explained based on Fick's law, as a square root of time-dependent diffusion process this relation can be utilized to explain drug dissolution from various types of modified drug release pharmaceutical dosage forms.

$$
Q_{t}=K_{H} V T
$$

Where $Q_{t}$ is the quantity of drug released at time $t$ and $K_{H}$ is Higuchi's rate constant, and if a plot of cumulative amount of drug release verses square root of time yields a straight line and the slope is 1 or more than 1 , then the particular dosage form is considered to follow Higuchi kinetics of drug release. In some experimental situations the release mechanism deviates from the Fick's equation, following an anomalous behavior (Non-Fickian release). In these cases a more generic equation can be used. Korsemeyer-Peppas developed a simple, semi-empirical, relating exponentially the drug release to the lapsed time.

$$
Q_{t} / Q_{\alpha}=K_{t}{ }^{n}
$$

Where $\mathrm{Q}_{t} / \mathrm{Q}_{\alpha}$ is the portion of drug released at time $\mathrm{t}$; $\mathrm{K}$ is the constant comprising a geometric and structural characteristics of the tablets; and $n$, the release exponent, is a parameter that depends on the release mechanism. The different release mechanism describe by peppas by using $n$ value. If the $n$ value is 0.5 or less, is Fickian diffusion release mechanism, and higher values $>0.5$ or $<1$, the release follows non-Fickian diffusion or anomalous transport. ${ }^{17-18}$ HixsonCrowell derived an equation to recognize that the area of the particle is proportional to the cubic root of its volume,

$$
\left[W_{o}^{1 / 3}-W_{t}^{1 / 3}\right]=K_{s} t
$$

Where $\mathrm{W}_{\mathrm{t}}$ is the remaining quantity of drug in dosage form at time $\mathrm{t}$, initial quantity of drug $\left(\mathrm{W}_{\mathrm{O}}\right)$, and $\mathrm{K}_{\mathrm{S}}$ is a constant incorporating the surface volume relation.

\section{Statistical analysis}

The dissolution rate and successive dissolution time of different optimized formulations were analyzed by one-way analysis of variance (ANOVA) using SPSS software (Version 12, SPSS, Chicago, United States). ${ }^{19}$

\section{Results and discussion}

The marketed Atorvastatin tablets were carried for general organoleptic test and processing problems/defects like capping, chipping and mottling. These tests were carried out by visual inspection, all the tablets were white oblong in shape except the brand $\mathrm{C}$ which is round and all show no defects on the tablets. The marketed tablets were assessed for their price. The results showed that there is significance difference in prices in Saudi Arabia, Lipitor (A) is almost double the prices of the brand $\mathrm{B}$ and $\mathrm{C}$ as shown in Table 1. The average crushing strength/hardness of all marketed tablets was in the range of 43.8-107.2N, therefore they are strong enough to withstand stress of handling and packing. The friability test were in the range of 
$0.0-0.32 \%$, according US Pharmacopeia if the friability is less than $1 \%$ the test passes. The weight variation test was found less than $3 \%$, none of the tablet deviate from the specified limit. The disintegration test for tablet should break within the time limit specified by the USP. The disintegration time of all the samples was within 5 minutes. According US Pharmacopeia it is specified that the film coated should disintegrate within $30 \mathrm{~min}$. The disintegration time for the entire tablet used in this study complies with the standard specifications. The drug content uniformity of the brands was $99.86 \%-107.21 \%$. The results of all official and non-official tests for all brands were found within the limit of pharmacopeia all test were passed as shown in the Table 2.

The in vitro drug dissolution from solid dosage form is necessary for drug bioavailability, particularly for poorly soluble drugs like Atorvastatin..$^{20}$ For this reason, after oral administration, disintegration studies can give an idea of the amount of drug available for absorption. The drugs which are poorly soluble in water have poor dissolution profile (rate determining step), they will not be sufficiently available in the body system to produce the desired therapeutic response..$^{22-23}$ The in vitro drug release from the samples at 10 minutes none of the tablet reaches $25 \%$ except sample A, it reaches around $27 \%$. At 20 minutes samples A and D show nearly $45 \%$ of drug release, while B and $\mathrm{C}$ show less than $40 \%$. At 30 minutes sample $\mathrm{A}$ shows more than $75 \%$ drug release, sample $\mathrm{C}$ and $\mathrm{D}$ shows nearly $64 \%$ drug release, Sample B shows least $40 \%$. At 50 minutes A, C and D were nearly $80 \%$ drug release, while sample B shows only $60 \%$. After 60 minutes sample A and C releases $100 \%$ and $104 \%$ of drug, whereas sample B and D shows $89 \%, 92 \%$ respectively as shown in Figure 2 . Sample C showed the highest percentage (104.33\%) of drug release and sample D shows the lowest percentage of drug release (88.92\%) from the different marketed samples ( $>0.05)$. The above in vitro drug release data of all samples give satisfactory results and releases almost $90 \%$ of drug release at $1 \mathrm{~h}$. One brand of AVS can be easily substituted to other marketed/commercial brand. Sample A was selected as the reference sample in this study; it is an innovator product among the various brands of Atorvastatin tablets available in Asir region of kingdom of Saudi Arabia.

Mathematical model fitting of obtained drug release data: To find out the best-fit mathematical model, the in vitro drug release data of AVS marketed tablets was fitted into different mathematical models, the best fit model with the regression coefficients values $\left(\mathrm{R}^{2}\right)$ or highest correlation coefficient for all formulations were as shown in Table 3 (PCP disso 2.08 version software, Pune, India). When the in vitro drug release data from the formulations were fitted to the Korsmeyer and Peppas equation (KPE), the values of $n$ obtained were $<1$ in all the cases. The $\mathrm{n}$ value ranged from 0.296-0.8364. The drug release mechanism was found to be fickian release for sample B and C, Nonfickian for sample A and D. Sample A and B were best fit to the $1^{\text {st }}$ order kinetic release, whereas $\mathrm{C}$ and $\mathrm{D}$ was matrix and peppas release model. The $\mathrm{n}$ value, the time exponent calculated from the KPE, was found to be less than 0.82 in innovator marketed tablets drug release profiles; consequently the release mechanism is recognized to be Nonfickian transport

Table I General description of atorvastatin marketed tablets in Asir region of Saudi Arabia

\begin{tabular}{|c|c|c|c|c|c|c|c|c|}
\hline Code & Brand name & $\begin{array}{l}\text { Manufacturing } \\
\text { company name }\end{array}$ & $\begin{array}{l}\text { Country of } \\
\text { origin }\end{array}$ & Batch no & $\begin{array}{l}\text { Manufactured } \\
\text { date }\end{array}$ & $\begin{array}{l}\text { Expired } \\
\text { date }\end{array}$ & Appearance & $\begin{array}{l}\text { Price } \\
\text { SAR }\end{array}$ \\
\hline $\mathbf{A}$ & LIPITORTM & $\begin{array}{l}\text { PFIZER/Jamjoom } \\
\text { Pharmaceutical }\end{array}$ & Jeddah KSA & J62697 & Jul-14 & Jun-17 & $\begin{array}{l}\text { White color } \\
\text { oblong shape }\end{array}$ & 125.4 \\
\hline B & LORVAST & Tabuk Pharmaceuticals & Tabuk KSA & $5 \mathrm{NK} 050$ & May-15 & May-17 & $\begin{array}{l}\text { White color } \\
\text { oblong shape }\end{array}$ & 67.2 \\
\hline $\mathrm{C}$ & LIPOMAX & SAJA Pharmaceuticals & Jeddah KSA & F150399 & Jun-15 & Jun-17 & $\begin{array}{l}\text { White color } \\
\text { oblong shape }\end{array}$ & 92.25 \\
\hline D & ASTATIN & $\begin{array}{l}\text { Jamjoom } \\
\text { Pharmaceuticals }\end{array}$ & Jeddah KSA & TC0082 & Mar-16 & Mar-18 & $\begin{array}{l}\text { White color } \\
\text { round shape }\end{array}$ & 74.7 \\
\hline
\end{tabular}

Table 2 Quality control evaluation of atorvastatin marketed tablets

\begin{tabular}{|c|c|c|c|c|c|}
\hline Code & $\begin{array}{l}\text { Hardness }(\mathbf{N}) \\
\left(\operatorname{Mean} \pm \text { SD }^{*}\right)\end{array}$ & $\begin{array}{l}\text { Friability }(\%) \\
(\text { Mean } \pm \text { SD } *)\end{array}$ & $\begin{array}{l}\text { Drug content }(\%) \\
(\text { Mean } \pm \text { SD } *)\end{array}$ & $\begin{array}{l}\text { Weight variation } \\
(\%)\end{array}$ & $\begin{array}{l}\text { Disintegration time } \\
\text { (Seconds) }\end{array}$ \\
\hline $\mathbf{A}$ & $83.3 \pm 0.53$ & 0 & $99.86 \pm 0.37$ & $0.664 \pm 0.07$ & 158 \\
\hline B & $107.2 \pm 0.29$ & $0.078 \pm 0.25$ & $100.79 \pm 0.42$ & $0.443 \pm 0.12$ & 150 \\
\hline $\mathrm{C}$ & $43.86 \pm 0.23$ & $0.065 \pm 0.09$ & $97.99 \pm 0.56$ & $0.659 \pm 0.55$ & 213 \\
\hline D & $78.18 \pm 0.14$ & $0.329 \pm 0.12$ & $107.21 \pm 0.19$ & $0.783 \pm 0.19$ & 255 \\
\hline
\end{tabular}


Table 3 Kinetic studies of dissolution profile of marketed atorvastatin tablets (values of $r 2, k$ and $n$ ) and mechanism of drug release

\begin{tabular}{|c|c|c|c|c|c|c|c|c|c|c|c|c|c|}
\hline \multirow[t]{2}{*}{ Code } & \multicolumn{2}{|c|}{ Zero order } & \multicolumn{2}{|c|}{ 1st order } & \multicolumn{2}{|l|}{ Matrix } & \multicolumn{2}{|c|}{$\begin{array}{l}\text { Korsmeyer- } \\
\text { peppas }\end{array}$} & \multicolumn{3}{|c|}{ Hix crow } & \multirow{2}{*}{$\begin{array}{l}\text { Mech. } \\
\text { of drug } \\
\text { release }\end{array}$} & \multirow{2}{*}{$\begin{array}{l}\text { Release } \\
\text { kinetics }\end{array}$} \\
\hline & $\mathbf{r}^{2}$ & $\mathbf{K}$ & $\mathbf{r}^{2}$ & $\mathbf{k}$ & $\mathbf{r}^{2}$ & $\mathbf{K}$ & $\mathbf{r}^{2}$ & $\mathbf{K}$ & $\mathbf{r}^{2}$ & $\mathbf{K}$ & $\mathbf{N}$ & & \\
\hline $\mathbf{A}$ & 0.9551 & 1.35 & 0.9927 & 1.54 & 0.9842 & 15.32 & 0.9757 & 3.55 & 0.9879 & 0.093 & 0.8227 & $\begin{array}{l}\text { Non- } \\
\text { Fickian }\end{array}$ & 1st order \\
\hline B & 0.9254 & 0.99 & 0.9912 & 0.02 & 0.9407 & 9.98 & 0.9389 & 12.11 & 0.941 & 0.06 & 0.4446 & Fickian & 1 st order \\
\hline $\mathrm{C}$ & 0.9763 & 1.84 & 0.9847 & 0.04 & 0.9776 & 18.93 & 0.9783 & 1.64 & 0.9806 & 0.01 & 0.296 & Fickian & Matrix \\
\hline D & 0.8738 & 1.32 & 0.9432 & 3.53 & 0.923 & 15.39 & 0.923 & 0.04 & 0.9068 & 0.091 & 0.8364 & $\begin{array}{l}\text { Non- } \\
\text { Fickian }\end{array}$ & Peppas \\
\hline
\end{tabular}

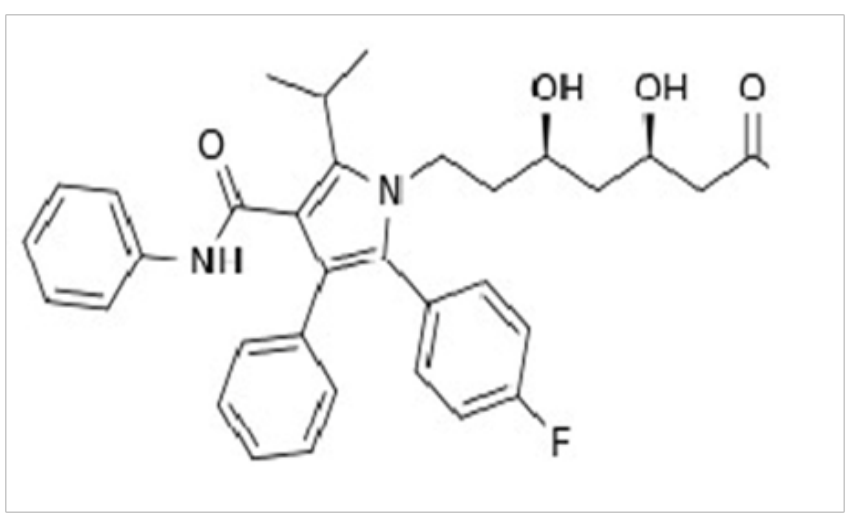

Figure I Structure of atorvastatin. Structure of atorvastatin.

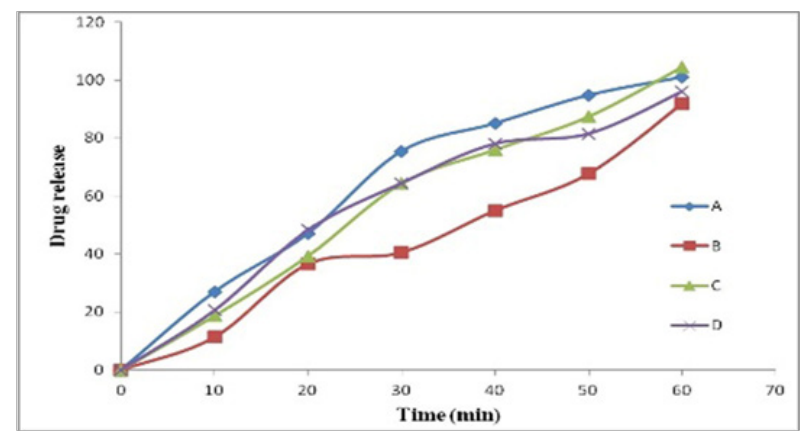

Figure 2 In vitro drug release of different marketed atorvastatin tablets (AD).

\section{Conclusion}

Atorvastatin Calcium is a well established first line lipidlowering drug. The current pharma industry market of Saudi Arabia is flooded with various brands of Atorvastatin tablet imported from Asia, Europe and Western countries. To compare and contrast the different brands of AVS tablets for their quality, the above study was carried out. The above results concluded that all brands of AVS show similar drug release from the tablets and all official and nonoffical tests were within US pharmacopeia limits. This will give very useful information to pharmacists, health care professionals while determining the interchangeability during prescribing and dispensing of AVS brands. Regarding the above data patient can select best cost effective (Pharmacoeconomic) AVS brand which are available in Saudi Arabian market. It gives ample information to the Ministry of Health, Kingdom of Saudi Arabia.

\section{Acknowledgements}

The authors would like to express their gratitude to King Khalid University, Abha, Saudi Arabia for providing administrative and technical support.

\section{Conflict of interest}

The author declares no conflict of interest.

\section{References}

1. Lennernas H, Fager G. Pharmacodynamics and pharmacokinetics of the HMGCoA reductase inhibitors: similarities and differences. Clin Pharmacokinet. 1997;32(5):403-425.

2. Atorvastatin calcium, monograph of atorvastatin; 2013.

3. Atorvastatin calcium tablets, description, FDA drug information.

4. Pekkanen J, Linn S, Heiss G. Ten-year mortality from cardiovascular disease in relation to cholesterol level among men with and without preexisting cardiovascular disease. N Engl J Med. 1990;322(24):17001707.

5. Istvan ES, Deisenhofer J. The structure of the catalytic portion of human HMGCoA reductase. Biochim Biophys Acta. 2000;1529(3):9-18.

6. Jones P, Kafonek S, Laurora I. Comparative dose efficacy study of atorvastatin versus simvastatin, pravastatin, lovastatin, and fluvastatin in patients with hypercholesterolemia (the CURVES study). Am J Cardiol. 1998;81(5):582-587.

7. Nagaraju P, Pasumarthy, Gopal NV, et al. Spectrophotometric methods for the determination of Atorvastatin calcium in pure and its pharmaceutical dosage forms. Asian J Research Chem. 2008;1(2):64-66.

8. Zaid AN, Natur S, Qaddomi A. Formulation and bioequivalence of two Valsartan/Amlodipine immediate release tablets after a single oral administration. Pak J Pharm Sci. 2014;27(4):755-762.

9. Zaid AN, Mousa A, Ghazal $\mathrm{N}$, et al. Interchangeability and comparative effectiveness between generic and brand montelukast immediate release tablets after a single oral administration in healthy volunteers. Clin Transl Allergy. 2015;11:5-37.

10. Dilshad H, Naveed S, Rafiq A. Comparitive study of four different brands of acetaminophen available in Karachi. WJPS. 2014;2(6):586-590. 
11. Kocic I, Homsek I, Dacevic M, et al. An investigation into the influence of experimental conditions on in vitro drug release from immediate-release tablets of levothyroxine sodium and its relation to oral bioavailability. AAPS Pharm Sci Tech. 2011;12(3):938-948.

12. Seitz JA, Flessland GM. Evaluation of physical properties of compressed tablets, 1: tablet hardness and friability. J Pharm Sci. 1965;54(9):13531357.

13. Lachman L, Lieberman HA, Kanig JL. The Theory and Practice of Industrial Pharmacy. 3rd ed. 1986;297:299-301.

14. United State Pharmacopeia (USP) XXVI, US Pharmacopoeial Convention, CD Rom version; 2003.

15. Wani TA, Khalil NY, Abdel-Rahman HM, et al. Novel microwell-based Spectrophotometric assay for Determination of Atorvastatin Calcium in Pharmaceutical Formulations. Chem Cent J. 2011;5:1-57.

16. Khan FN, Dehghan MHG. Enhanced bioavailability and dissolution of atorvastatin calcium from floating microcapsules using minimum additives. Sci Pharm. 2012;80(1):215-228.

17. Peppas NA, Franson NM. The swelling interface number as a criterion for prediction of diffusional solute release mechanisms in swellable polymers. J Polym Sci Polym Phys. 1983;21(6):983-997.
18. Korsmeyer RW, Gurny R, Doelker E, et al. Mechanisms of solute release from porous hydrophilic polymers. Int J Pharm.1983;15(1):25-35.

19. Srikanth MV, Rao NS, Sunil SA, et al. Statistical design and evaluation of a propranolol $\mathrm{HCl}$ gastric floating tablet. Acta Pharmaceutica Sinica B. 2012;2(1):60-69.

20. Safila Naveed, Tanweer Alam, Asra Hameed, et al. UV spectrophotometric method for estimation of ofloxacin in tablet dosage form and comparative study of its two brands. J Bioequiv. 2016;8(3):125-127.

21. Dilshad H, Naveed S, Waheed N. Comparitive study of four different brands of captopril available in Karachi. Int Res J Pharm. 2014;5(3):374 377 .

22. Nayak AK. Comparative In Vitro dissolution assessment of some commercially available paracetamol tablets. Int J Pharm Sci. Rev and Res. 2010;2(1):29-30

23. Moshood OA, Oladapo I, Patricia NN, et al. Quality of Brands of Atorvastatin calcium tablets marketed in Lagos, Nigeria. Int J Pharmacy \& Pharmacol. 2012;1:1-7. 